\title{
International Outsourcing of Research and Development: A Model of Leadership and Culture
}

\author{
Cliff Allen \\ School of Business Administration, Portland State University \\ 631 SW Harrison Street, Suite 463, Portland, OR 97201, USA \\ E-mail: cliffa@ sba.pdx.edu \\ Harm-Jan Steenhuis \\ College of Business and Public Administration, Eastern Washington University \\ 668 N. Riverpoint Blvd., Suite A, Spokane, WA 99202, USA \\ E-mail: hsteenhuis@ewu.edu (Corresponding Author)
}

\begin{abstract}
As innovation has been outsourced globally, it has joined manufacturing organizations consisting of diverse cultures, geographies, and partnerships. The use of third-party resources to manage design and innovation has resulted in a new system of knowledge management. As the industry's organizational and financial boundaries have attenuated, a new type of leadership challenge has emerged, creating the research question: Are there leadership practices or styles that effectively guide organizations that rely on the outsourcing of innovation and manufacturing to Taiwan and China in the computing industry? A qualitative case study method was used to investigate the differing leadership practices applied within a dialectic global production network in which a system of innovation and manufacturing has emerged. The analysis considers a full range of leadership behaviours used when facing the challenges of outsourcing $R \& D$.
\end{abstract}

Keywords: $R \& D, R \& D$ internationalisation, $R \& D$ collaboration, leadership

\section{INTRODUCTION}

Cost containment is at the centre of development and manufacturing of products and has led to the outsourcing of manufacturing. Outsourcing is generally defined as the purchase of a component, assembly, process, or service from an outside supplier (Monczka, Trent and Handfield, 2002). Since manufacturing has been outsourced to low-cost centres throughout the world, other activities such as research and development (R\&D) have also been considered for outsourcing. R\&D was traditionally not considered for outsourcing since it was considered as a core competence (Lynn \& Salzman, 2007). When R\&D becomes part of the outsourcing strategy, the boundaries of innovation ownership attenuate, creating challenges that have not been experienced with the outsourcing of manufacturing (Leifer, O'Conner, \& Rice, 2001). By relinquishing design decisions, the potential has been created for losing the "span of control in the core competencies" of the organization (Brown \& Wilson, 2005). A new strategic leadership vision is required to include strategies for implementing changes such as outsourcing, with an eye toward the entire firm's collective efficacy regarding future innovation (Lynn \& Salzman, 2007). Thus, leading cross-cultural $\mathrm{R} \& \mathrm{D}$ located in different time zones has generated new leadership challenges.

Research on international $\mathrm{R} \& \mathrm{D}$ has looked at several issues such as managing multinational R\&D or technology transfer within multinational R\&D (Cheng and Bolon, 1993), drivers and motives for global $R \& D(W u, 2007)$ as well as how certain nations are catching-up with their innovative capabilities (Ernst, 2005; Wu, 2007), international property protection in R\&D collaborations (Bader, 2008), partnership issues (Feller et al., 2009; Vonortas and Okamura, 2009), competence and performance of R\&D subsidiaries (Furu, 2001; Grevesen and Damanpour, 2007). However, research into leadership related to the implementation of outsourcing of $R \& D$ is limited. The purpose of this article is to contribute to understanding leadership of international outsourcing of $\mathrm{R} \& \mathrm{D}$

One of the high technology industries affected by outsourcing has been computer manufacturing. This has for example led to a study on the concern of losing jobs in the US (Kelly et al., 2004). Although in many industries the practice of outsourcing $R \& D$ is relatively new, it is now commonplace in the PC (personal computing) industry (Dedrick \& Kraemer, 2006). The leading PC companies have migrated to Asia, where the engineers reside (Liu \& Chen, 2003).Therefore this industry is considered a good industry for the research project. The central research questions were formulated as: what type of leadership is the best approach for leading R\&D outsourcing from the US to Asia in the PC industry? When dealing with international situations, culture often has a big influence. This led to the second question: how is the leadership approach affected by cultural characteristics?

\section{LITERATURE REVIEW}

The two main topics of the research are leadership characteristics related to the influence of culture on outsourcing (2.2) and leadership characteristics related to outsourcing (2.3). Before covering these two topics, leadership will be discussed in more general terms. 


\subsection{Leadership}

There are four generations of theory on leadership: trait theories, behavioural theories, contingency theories, and transformational theories (Van Maurik, 2001). The focus in this study will be on the last generation. Transformational theories state that leaders who transform organizations inspire followers by creating a common vision and clearly communicating the importance of achieving the goal. They also embody behaviour that inspires and encourages followers to take risk and work as a team towards goal completion (Bass \& Riggio, 2006). This contrasts with transactional leadership which emphasizes contingent rewards such as bonuses and pay raises.

Leadership of internal R\&D: Transformational leaders foster innovation and a supportive approach to $R \& D$ groups. In the technology industry, an effective leader is one who invests in knowledge creation internally, but also is able to exploit innovation by acquiring it externally (Makri \&
Scandura, 2010). Therefore, the skills required to lead, both within and between organizations that are part of the global production network, are different from those of earlier models (Ernst \& Kim, 2002).

Leadership of external R\&D: Research has focused primarily on direct transformational leaders, not on how to motivate organizations indirectly or from a physical or organizational distance (Hannah \& Lester, 2008). Distance leadership encompasses relations across echelons outside both organizational and corporate boundaries (Jung, Chow, $\& \mathrm{Wu}, 2003)$. Distant leaders face many new organizational challenges and priorities when dealing with third parties. Jung, Wu, and Chow (2008) proposed that these new priorities, including the protection of intellectual property, growth of core innovation capabilities, and balancing thirdparty relationships, requires a transformational leader who motivates all segments of a global model.

Table 1. Comparison of leadership, adopted from Doyle and Smith (1999)

\begin{tabular}{|l|l|}
\hline \multicolumn{1}{|c|}{ Transactional leader } & \multicolumn{1}{c|}{ Transformational leader } \\
\hline $\begin{array}{l}\text { Recognizes what it is that we want to get from work and tries to } \\
\text { ensure that we get it if our performance merits it }\end{array}$ & $\begin{array}{l}\text { Raises our level of awareness, our level of consciousness } \\
\text { about the significance of value of designated outcomes, and } \\
\text { ways of reaching them. }\end{array}$ \\
\hline Exchanges rewards and promises for our effort & $\begin{array}{l}\text { Gets us transcend our own self-interest for the sake of the } \\
\text { team, organization or larger polity. }\end{array}$ \\
\hline $\begin{array}{l}\text { Is responsive to our immediate self interests if they can be met by } \\
\text { getting the work done }\end{array}$ & $\begin{array}{l}\text { Alters our need level (after Maslow) and expands our range } \\
\text { of wants and needs }\end{array}$ \\
\hline
\end{tabular}

\subsection{Leadership and culture}

Culture can be viewed as the collective programming of the mind which distinguishes the members of one group or category of people from another (Hofstede, 1997). House (2004) stated that as "economic borders come down, cultural barriers could go up, thus presenting new challenges and opportunities in business." These barriers come in many dimensions of culture and language. Leaders must balance these as organizations establish cross-border strategic goals such as outsourcing design innovation.

Cultural complexities and values have been researched extensively. One of the main contributions has been a categorization into cultural dimensions such as power distance, collectivism versus individualism, uncertainty avoidance, and assertiveness (Hofstede \& Hofstede, 2005). The varying types of leadership behaviors can be effective given the type of cultural dimension an organization has established. For example, people in Chinese organizations in the area of power distance are more comfortable with inequality and a transactional relationship with their leaders that is distant. While in US organizations people in the area of power distance prefer an transformational affiliation of consultation and interdependence (Hofstede \& Hofstede, 2005). Another example is along the assertive dimension which in Chinese cultures tends to be low, as people from this culture generally are concerned with team-oriented, collectivist behaviors. Therefore, a highly relational, transformational team-oriented leader is not as positively related to assertiveness in a Chinese organization as it is in a US group that strives for individual inspiration from highly assertive leaders (Hartog, 2004).
Based upon the above discussion it can be concluded that culture plays an important role for leading the international outsourcing of R\&D. The literature indicates that transformational leadership is the best approach for leading international teams and that communication is a key issue for leaders. However, how to communicate, and how to take cultural differences into account when leading crosscultural teams are still not entirely clear. One objective of this research is to contribute in this area.

Table 2. Examples of culture and leadership

\begin{tabular}{|c|c|c|}
\hline & US culture & $\begin{array}{c}\text { China culture } \\
\text { (example) }\end{array}$ \\
\hline Power distance & Low & High \\
\hline Assertiveness & Low & High \\
\hline $\begin{array}{c}\text { Degree of } \\
\text { collectivism }\end{array}$ & Low & High \\
\hline $\begin{array}{c}\text { Uncertainty } \\
\text { avoidance }\end{array}$ & Low & High \\
\hline Leadership & Transformational & Transactional \\
\hline
\end{tabular}

\subsection{Leadership and outsourcing}

Through outsourcing to low-cost regions, products have become cheaper and often faster to manufacture. The need for leadership regarding how and when to invest in outsourcing partners is greater than ever, as the "how, when, and where to outsource seem to be made opportunistically 
without concern over the core competence of the firm" (Lynn \& Salzman, 2007).

When outsourcing manufacturing, success is dependent upon clear codified specifications and efficient modes of technology transfer (Brown \& Wilson, 2005). The ability of an outsourced partner to succeed requires the tracking of specific task oriented outcomes (Brown \& Wilson, 2005). To establish realistic agreed upon tactical measures of performance, successful leaders may practice transactional leadership, which includes bonuses and task oriented management (Bass \& Riggio, 2006).

The momentum has now shifted towards outsourcing R\&D (Wadhwa, Gereffi, Rissing, \& Ong, 2007). The leadership skills required to manage outsourced $R \& D$ are different from those needed for manufacturing operations (Florida, 1997; Zhao \& Arvantis, 2010). With the outsourcing of $\mathrm{R} \& \mathrm{D}$, greater creativity and risks are necessary requiring leadership practices that inspire followers to embrace "out-of the-box thinking and adopt creative and exploratory thinking processes" (Jung, Wu \& Chow, 2008). Based on this it can be concluded that one leadership issue for outsourcing $R \& D$ is to create an innovative organization by motivating people across different organizations, with different cultures and with different scientific knowledge about product development, i.e. it calls for transformative leadership.

Multicultural distant leaders face many new organizational challenges and priorities within the global production network. Jung, Wu, and Chow (2008) proposed that these new priorities, including the protection of intellectual property, growth of core innovation capabilities, and balancing third-party relationships, requires a transformational leader who motivates all segments of a global model. In addition, Kahai and Avolio (2008) suggested that a mixed model of transactional motivation and transformational visionary leadership would be effective in a global context.

Table 3. Examples of type of outsourced activity and leadership

\begin{tabular}{|c|c|c|}
\hline & Manufacturing & R\&D \\
\hline $\begin{array}{c}\text { Level of codification } \\
\text { Characteristics }\end{array}$ & High, i.e. clear codified \\
\hline Mode of technology transfer & $\begin{array}{c}\text { Established and efficient, i.e. codified } \\
\text { information is shared }\end{array}$ & Much is oral communication \\
\hline Performance measurement & $\begin{array}{c}\text { Tracking of specific task oriented outcomes } \\
\text { Leadership }\end{array}$ & $\begin{array}{c}\text { On-time and on-budget project completion } \\
\text { to agreed specifications }\end{array}$ \\
\hline
\end{tabular}

Based upon the above discussion it can be concluded that leading the outsourcing of design faces different challenges than the outsourcing of manufacturing operations. How to lead the outsourcing of design is still rather vague as much of the literature has focused on transactional leadership while some argue for transformational leadership or mixed models. This research is oriented on contributing in this area.

\subsection{Conclusion}

Previous studies that were oriented on outsourcing have focused mainly on manufacturing but outsourcing R\&D has received relatively little attention. In the field of leadership results have been inconclusive with regard to the best leadership approach when managing from a physical distance. This implies that more studies are required to get insight into leadership approaches for outsourcing of R\&D activities. Two items have been identified in previous studies. First, the type of activity (manufacturing versus R\&D) seems to influence leadership style and second, the national culture where the activity takes place seems to influence leadership style. There is no information on the trade-offs that might be necessary if these are two factors are conflicting. The purpose of this paper is to examine both factors simultaneously and determine the trade-off issue instead of the previous studies which looked at one of the two factors.

\section{METHODOLOGY}

The purpose of the study was to increase the understanding of how leadership styles guide computing organizations that outsource R\&D. Effectiveness was measured by the leadership that led to on-time and on-budget completion of projects while adhering closely to the marketing specification. Since outsourcing was to Asia, the research moved from one culture to another. Therefore, a case study approach was followed as it effectively investigates real life experiences and attach meaning to existing leadership behaviors.

\subsection{Case selection}

A decision was made to study the outsourcing of two design projects in Asia that occurred simultaneously. This allowed for direct comparison and contrast between the two cases. The study focused on evaluating ways in which effective leaders interact with virtual teams and how these styles affected outcomes. In addition, the selection of two distinctly different projects, managed by different Original Design Manufactures (ODMs) and a single Multinational Corporation's (MNC) Project Managers, increases validity (Stake, 1995). The firm in this study was a laptop computing company labelled MNC, and which used the outsourcing model consistent in the industry (Dedrick \& Kraemer, 2008). The study examined one outsourcing US-based MNC firm, but the two projects were at two distinct ODMs. 
In Figure 1, these were labelled ODM I (Taiwanese but with operations in China) and ODM II (Taiwan-based). In the first case the major activities in the projects were shared with the MNC once the product specification was complete then co-ownership of design, manufacturing, and quality existed. This is represented by the two-way relationship between the ODM I and MNC boxes. In the second case once the specification was agreed upon, the relationship between the MNC and the ODM II was more one direction as is shown between the boxes with the one direction arrow.

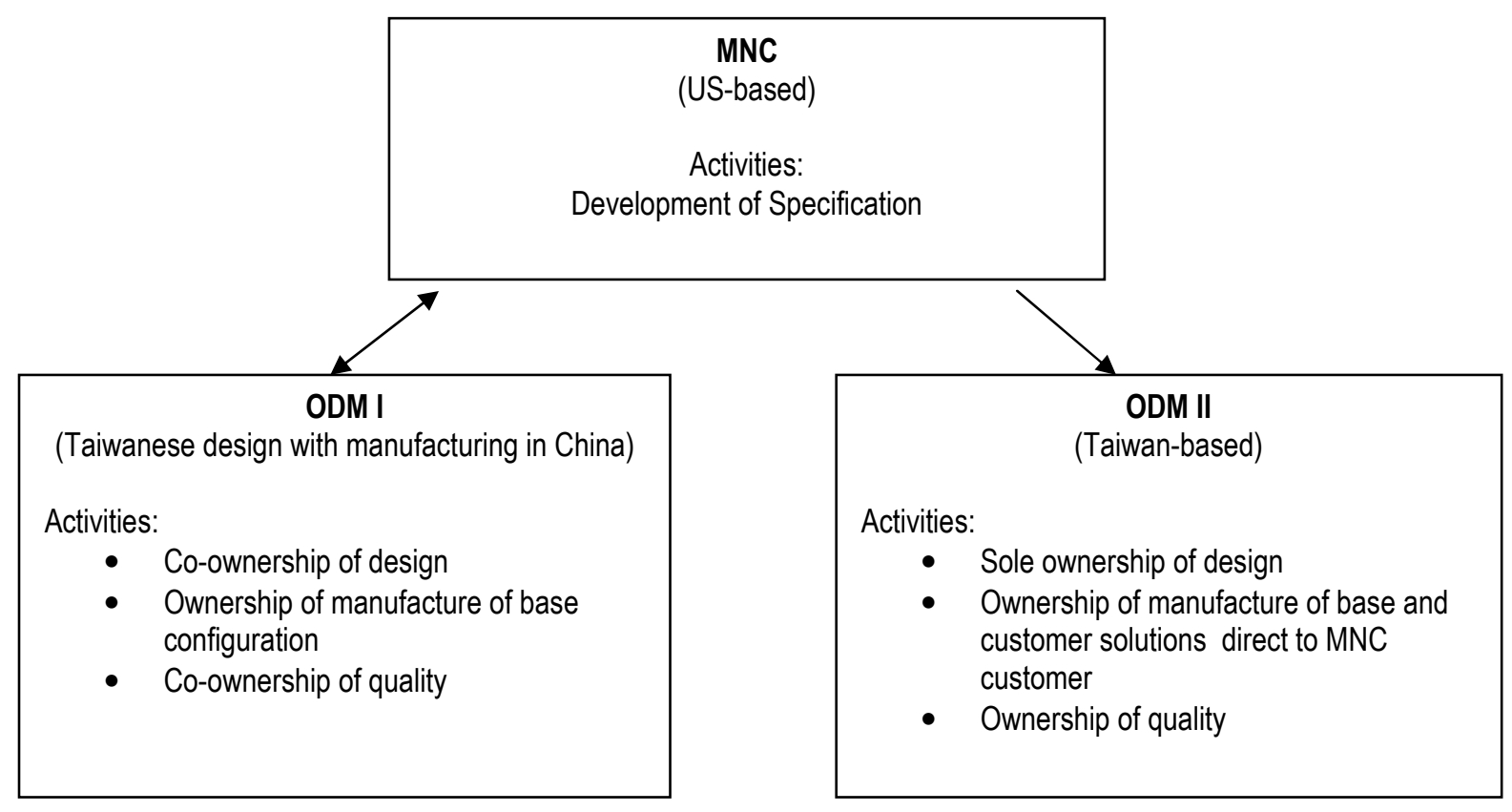

Figure 1. Overview of the two cases

\subsubsection{Organisational Structure}

The organisational structure of the MNC was similar in both cases. The MNC set up the communication to be managed by a Project Manager who controlled the R\&D milestone schedule for project completion. In each functional area; purchasing, quality, engineering, and marketing, there was a leader who interacted with their counter part in the ODM. From a leadership perspective, the MNC viewed the ODM model as new but essential for quick and cost effective design. Therefore, the MNC leaders communicated the company and market vision for the products and customers to the ODMs. This transformational approach was meant to energize the ODMs to apply proper resources for project completion. Within the ODM, the leadership was transactional based on compensation for project completion, however outward leadership practices with the MNC tended toward transformational as the ODMs accepted the western style of leadership.

\subsubsection{First case}

The first case was a project between the MNC and ODM I which was a tier II, or smaller ODM with design resources in Taiwan and manufacturing in China. The project assigned was the second major undertaking between these two parties. It represented on ongoing relationship that spanned beyond six years. The goal of ODM I was to remain a niche player in order to improve the overall quality and innovation of its own computing products. While some Taiwanese ODMs design and produce only other customer's products, ODM I continued to market and sell its own branded computers. This is a significant difference between ODM I and ODM II, as ODM I was smaller and the MNC felt they were less likely to include IP that would help their products into the
MNC competitors products developed by ODM II. The improvement of ODM I products came through the knowledge gained from various projects with several MNCs. The MNC was comfortable with the shared use of limited intellectual property (IP) if the innovation was created by the ODM or a result of collaborative design work. This was an example of the acceptance and realization by many MNCs that the leakage of IP into ODM technology is a by-product of the risk of outsourcing to gain access to low-cost design resources (Thursby \& Thursby, 2006).

\subsubsection{Second case}

The second case was a project between the MNC and ODM II, a first tier ODM, one of the three largest ODMs in Taiwan. ODM II was undertaking their second consecutive large project with this MNC. This was a relationship that spanned four years at the time of the study. The goals of ODM II were to be a significant designer of mobile computing devices of all shapes and sizes, applying their large manufacturing and design expertise to improve procurement leverage and quality. ODM II was very confident in their ability to innovate and design computing equipment and preferred to independently work from a MNC supplied specification. While this was enticing to the MNC, it was also an example of the potential of complete loss of control when outsourcing R\&D in computing equipment

The partnership with ODM II was established to take advantage of size and vast resources at a first tier ODM. Unlike the decision to engage the hands-on approach of ODM I, the engagement of ODM II was made by executive management of the U.S.-based MNC. Since this relationship was to be hands-off and less directive, greater reliance on trust and the establishment of a product vision for the market and the two organisations was required. The need for greater 
trust and reliance on relationships created an opportunity to view leadership practices that transformed how the MNC managed the relinquishing of control and how ODM II generated the design creativity the MNC required.

\subsection{Data collection}

This study was bound by the design cycles of the two projects that took place over a period of eighteen months, completed in the year 2007. Data collection was based on multiple sources of evidence. Two categories of informants were asked to participate in the study: the executive leaders of the division or department accountable for the product design and the team leaders and followers involved with the designing the products. The participants represented those who were accountable for the project completion therefore, it was anticipated that participants in this group would generate conversations with experts in other subject matter areas and ultimately lead to saturation of the data. Since Seidman (2006) suggested that approaching close to 25 participants is a good representation to ensure saturation, the plan was to start with targeted participants as well as use the snowballing strategy. Ultimately, twenty-two participants, including ODM participants from Mainland China and Taiwan, as well as members of the MNC in the United States and Taiwan, were questioned.

\section{CASE DESCRIPTIONS}

\subsection{First case}

The partnership with the second tier ODM in this case required intensive daily involvement from the $\mathrm{MNC}$ due to the smaller size and the resources available. The project was conducted over an 18 month period beginning with conceptual marketing planning over a 6 month period and 12 months for R\&D. Interaction was frequent with conference calls twice weekly and project reviews conducted often in Taiwan or the U.S. The transition from earlier experiences between the two parties with outsourcing manufacturing to the new experience of outsourcing $R \& D$ was challenging.

The leadership approach was transformational leadership which appeared helpful at all levels of the MNC and ODM organizations, specifically at the start of a project as the MNC Project Manager pointed out:

I think we did a pretty good job upfront of saying this is why we are doing what we are doing at a strategic level, and that for the ODM was translated into here's our end customers, here's how it could benefit [the ODM] in a different category of product, and then unit volume which is what they were looking for.

Transformational leadership was considered the most appropriate leadership approach by the MNC leaders; as the MNC Executive VP expressed:

You have to over-communicate and make sure the team 5,000 miles away is over-communicated to. However, communication was not without leadership challenges as the ODM Project Manager of the shared this concern over MNC engineers tending to keep knowledge of the product at the MNC site, expressing:
We needed to sync these two [design] processes together, and when we work with the [MNC] team we used their terminology. So in the beginning we need to work with the [MNC] stakeholders for everybody to be on the same page.

Taking risk and being assertive was one of the cultural issues at the start of the project, but as transformational attributes of communication and having common objectives were established, the ODM engineers started to take more design risk. The MNC Project Manager stated that at the beginning, understanding that lack of assertiveness at the ODM was the need to evaluate and commit to an idea. He shared:

I would say that the Asian culture on the engineering side, instead of saying no upfront, they will say I will study and perhaps get back to you later. That is the tendency and it can hinder the relationship, but I think once committed, they are willing to spend time to try and do it.

At the beginning of the projects, ODM I displayed behavior that appeared to conform to the assertive attitude that the U.S. MNC valued. ODM I tended to say "yes" to every request. This led to the realization that what was perceived to be assertive behavior was actually the expression of the Confucian value of saving face with the boss or customer. The leadership practice utilized to overcome this issue was establishing a sense of guanxi, or relationships in which openness and the willingness to express problems became less confrontational.

Overall, the relationship between ODM I and the MNC was the U.S.-based participants first experience with the MNC/ODM model. While they were still learning how to best implement and lead projects, there was heavy involvement from the U.S. participants in decision making and ODM I was comfortable with the hand-on participation of the MNC since they were small in size. The transformational leadership practices of communication and vision establishment overcame many of the cultural differences in power distance, assertiveness, uncertainty avoidance, and collectivist or individualist dimensions. All the participants mentioned that by the third major design cycle the leadership appeared much more comfortable and able to address confrontations quickly. The third design cycle and the project analyzed in this study was in year four of the MNC and ODM I relationship.

\subsection{Second case}

The second case was a project that developed over a 20 month time period beginning with a conceptual marketing investigation of over 8 months and 12 months for R\&D. As in the first case, the transition from strictly manufacturing to design of a new type of device brought additional leadership challenges. The emphasis changed from dictatorial focus on manufacturing specifications to collaboration on design. The MNC Project Manager summed up the differences when including innovation in the outsourcing model as including relationships:

The manufacturing piece is much more dictatorial. I mean by [including] design I viewed it as one big team. We were all working together, and so the watchwords were collaboration and respect. 
And the MNC Quality Manager emphasized trust and relationships, he stated:

I know that the Asia teams were very much, you know, about relationships and building that relationship with their partners and making sure that they maintained a good relationship.

Transformational leadership emphasizes communication, which became central to the success in outsourcing of R\&D. The MNC found that sharing their vision and requirements for their customers were important, but so too was listening to the ODM's concerns. In addition, to achieve the value of quicker time-to-market and low-cost design, the MNC had to relinquish their control over $R \& D$ as the ODM executive stated:

The primary reason to drive offshore development and manufacturing is to shorten the time to market and reduce costs. As the [MNC] began to take their hands off the project and seriously listen to what the ODM had to say, the working model changed and it turned out to be a much more successful project.

Overall, the leadership between the MNC and ODM II was consistent with the transformational style. Participants pointed out that there was significant effort on the part of ODM II to adapt to the business needs of the MNC through the adoption of English as a standard vehicle of communication. In addition, both ODM II and MNC emphasized the importance placed on communication and building relationships as a noteworthy contributor to the model's success. Similar to the challenges faced with ODM I; power distance, assertiveness, uncertainty avoidance, and collectivist or individualist dimensions were addressed with transformational practices of relationship building and communication. The difference with the ODM II relationship was a high-level style of concentrating less on product specifications and more on the market and the MNC customers as a vision for ODM II design. The participants noted that ODM II did not have their own product brand and that they were likely going to use the MNC IP in competitor's products. This was another of the mid-level follower's complaints where the establishment of the ODM II partnership was not consensual and was not clearly addressed by the MNC leadership.

\subsection{Leadership at the MNC after outsourcing}

While the experiences of the ODM participants in both cases were generally positive, generating leadership practices that motivated the U.S.-based MNC designers was difficult in the MNC/ODM model. The outsourcing of R\&D created new stresses. One MNC leader felt that the new model was pushed upon them without a vision or explanation, while the executive leader believed he had allowed for too much "collaborative discussion" about the transition. The executives at the MNC practiced relationship based transformational leadership with the ODM, but were reduced to command and control transactional leadership with the engineers at the MNC site.

The ODM team was traditionally used to transactional and internal bonuses to complete projects, thus the usual ODM behavior was a transactional leadership style of contingent reward as the basis for managing projects initially. While initially the ODM emphasized transactional leadership internally, the transformational style practiced between the MNC and ODM led to a successful project. The more the ODM learned about the MNC markets and products, the more enthusiastic the ODM design team became, as the Engineering Manager at the ODM expressed:

At the beginning we were not convinced. However, after we see the idea, I think that really impressed others. We started to see the possibilities, to think,

"Yeah maybe this is the way we should go.

However, in the U.S., the MNC engineers started to feel disenfranchised as the design work was sent offshore. Since the MNC leaders did not take the time to motivate the designers in the U.S. by expressing how the ODM model fit with the MNC goals, the designers were left to wonder what the next steps would be and how this affected them individually. Thus an ineffective or transactional approach was followed. This was recognized by the ODM design leaders who felt that the lack of outsourcing acceptance on the part of the MNC's R\&D teams was hindering the project. The domestic leaders that began to rely on the MNC/ODM model felt strong conflicting emotions and opinions about the migration of design expertise and ultimately jobs to the offshore partners. However, they were unwilling to address the outsourcing of $\mathrm{R} \& \mathrm{D}$ at home the same way they motivated the ODM leaders and engineers.

\subsection{Leadership and Virtual Teams}

Leadership theories that are effective in dyadic relations may not be as successful in globalized environments. When evaluating successful global leadership, it is helpful to address traits that may apply to multinational organizations. One leadership style that appears to navigate through the complexity of leadership at a distance by emphasizing communication and motivation is transformational leadership. In the cases researched, the overarching emphasis was on leaders who communicated and were willing to travel or discuss issues all hours of the day. As the Executive from the MNC suggested:

I think you have to over-communicate. The other [leadership] stylistic difference is you just got to be prepared to work, you know, some pretty funky hours. My routine was I would get up and at 4:30 in the morning I would be on the phone [with Asia].

The emphasis on transformational leadership and creating a common vision was expressed as critical by the MNC Project Manager:

You need a common cause in order to be an effective team. So how are we going to create that when we are however many thousands of miles apart, different languages, and utterly different time zones? So communicating to me was the same as trying to create the illusion that we were all in the same building.

However, in the end, nothing could replace the power of face-to-face meetings as expressed by the ODM Program Manager:

Usually face-to-face meetings can communicate more efficiently, e-mail or telephone, there is always something lost. In some ways, the customer's voice is louder than the internal customers. 


\section{MODEL DEVELOPMENT}

Overall, the findings revealed the presence of both effective and ineffective leadership styles. First, a full range of leadership practices were used in both projects and in each location. The full range of leadership included an emphasis on communication, nurturing relationships, use of contingent rewards, and the establishment of a vision or a common set of goals for the MNC and original design manufacturers (ODMs) teams to follow. The second major theme involved the leadership practices applied to motivate the U.S.-based leaders and engineers when outsourcing R\&D. These leadership practices included the establishment of the MNC/ODM outsourcing model through communication, providing empowerment, and changes to the responsibilities of followers that integrated into the model. It is important to note that the leadership practices encompass both behaviors intra and inter-firm when outsourcing $R \& D$. Traditional leadership behaviors changed with the outsourcing of R\&D which required adjustments from the MNC and ODM leaders collaborating both between teams and internally. However, preceding the overall acceptance of the MNC/ODM model was the presence of transactional leadership styles within the MNC organization, initially leading to job loss for U.S. based engineers and limiting the effectiveness of the groups.

The leadership traits, cultural dimensions, and the uniqueness of outsourcing R\&D in the ODM model have been highlighted in the literature. From the similarities found in the two distinct MNC projects, the conclusion is that leadership behaviors and cultural dimensions influence the success of outsourcing innovation design. In addition, it appears that time and trust play a part in the ability to fully transition to an effective ODM model. Based on the literature as well as the case findings a model was developed, see Figure 2.

On the one hand, cultural factors play a role. The cultural characteristic of power distance and the leadership practice of communication are displayed based on the expectation of inequality inside organizations' correlating with less communication (Hofstede, 2001, p. 79). In Chinese organizations, people are more comfortable with inequality and a relationship with their leaders that is distant, while Western followers prefer an affiliation of consultation and interdependence (Hofstede \& Hofstede, 2005). Thus, a higher power distance calls for a lower degree of transformative leadership, i.e. transactional approach.

The assertive dimension in Chinese cultures tends to be low, as people from this culture generally are concerned with team-oriented, collectivist behaviors. A highly relational, team-oriented leader is not highly associated with assertiveness in a Chinese organization (Hartog, 2004). Thus, higher values on assertiveness call for a higher degree of transformative leadership, i.e. transformative approach.

With regard to the dimension of uncertainty avoidance, past findings such as Sully de Luque and Javidan (2004) expressed, those "societies more tolerant of uncertainty ... report higher rates of innovation than societies less tolerant of uncertainty." Organisations that score high on uncertainty avoidance tend to respond positively to leaders who establish rules and firm procedures, whereas those that prefer low uncertainly avoidance show less resistance to change and risk taking as is established by transformational leadership. Thus, higher levels of uncertainty avoidance calls for a lower degree of transformative leadership, i.e. transactional.

The dimension of collectivism and the negative relationship with the leadership behavior of empowerment is displayed in Figure 2. The Chinese are a highly collectivist society concerned with the needs of the group and less with the individual (Triandis, 2001). The collectivist groups generally take direction from leaders and display their respect through loyalty and adherence (Gupta et al., 2004). Thus, higher levels of collectivism, calls for lower levels of transformative leadership, i.e. transactional.

On the other hand, the type of activity that is outsourced also plays a role. The participants expressed that an emphasis on communication was a byproduct of migrating to an outsourcing model that included $R \& D$, as the ODM designers needed to buy into the product vision to increase creative outcomes. Thus, the lower the degree of codification (R\&D compared to more codified manufacturing), the higher the need for communication. Furthermore, the higher the need for communication, the higher the degree of transformative leadership.

The MNC leaders emphasized communication and the vision of the projects, which empowered the ODM designers to create solutions to fit the need of the MNC customer. The empowerment of the ODM group by the MNO leaders is positively associated with degree of transformative leaderhip when designing products. But, when manufacturing to a specification, i.e. the knowledge exchanged is highly codified, then generally empowering change is not necessary. When design is included, the exchange of ideas can alleviate project delays. In the findings, the MNC leaders found that empowerment of the group to make decisions led to greater creativity, i.e. the lower the degree of codification (R\&D/creativity versus manufacturing) calls for a higher degree of empowerment. Furthermore, a higher degree of empowerment calls for a higher degree of transformative leadership.

In addition to these two sets of variables that affect the leadership style, there are trade-offs among these variables. For example due to the high power distance in China, a transactional leadership approach was expected. The findings revealed that the MNC leaders practiced highly communicative transformational values by establishing a vision for the projects, which proved successful in generating ODM design creativity. This was opposite what was expected but is connected with the need for communication due to characteristics of R\&D.

Power distance is also connected with the level of empowerment. In high power distance Chinese organizations, empowerment would be low, as the East expects direction from patriarchal "headship" leaders (Shaw, 1990). However, the MNO leaders felt that they needed to communicate and establish relationships that would lead to empowerment for the ODM designers to take risks and generate creative designs. Thus, again, the characteristics of R\&D were more important than the cultural influence. 


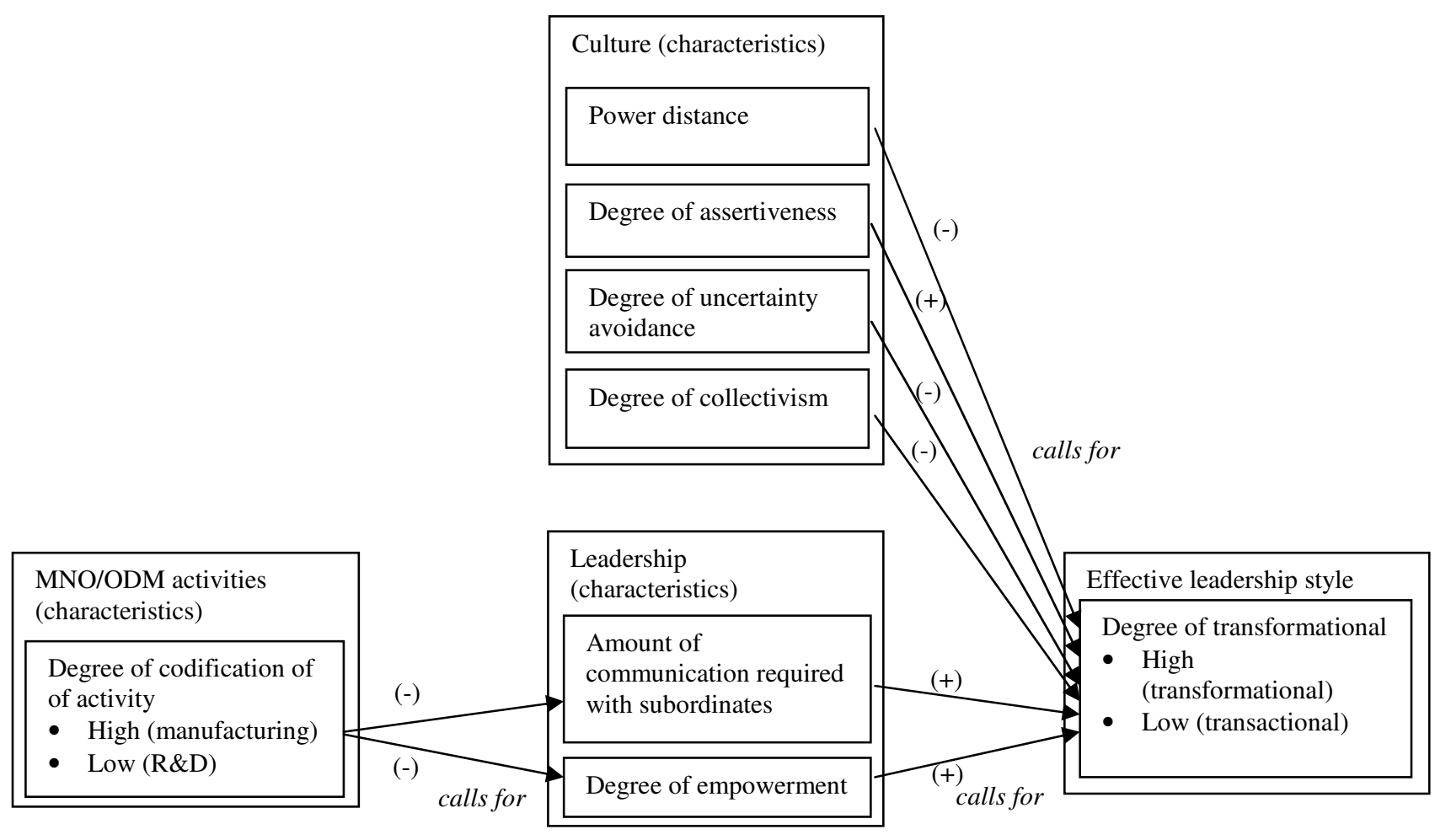

Figure 2. Expected relationships among the characteristics of culture and MNO/ODM activities linking them to leadership.

The findings revealed that assertiveness was important to communicate the issues with design or project delays. The MNC leaders found that by increasing their emphasis on relationships or guanxi, the ODM design teams would take more risks and display assertive communications when problems arose. The participants pointed out that risk taking and creative feedback were not only welcome, but also necessary when outsourcing design. Alternatively, highly assertive behavior was not expected when manufacturing was outsourced.

Based on a higher level of uncertainty avoidance in China, a transactional approach was expected to be the most effective. Based on the model, low risk taking cultures might be the best at housing new product implementation while high risk taking groups might be best at idea generation. Since the marketing specifications were compiled by the MNC and then transferred to the ODM for development, the degree of risk may have been tolerable for the ODMs since they were providing $R \& D$ within specific guidelines. In both instances of risk tolerance, the teams must trust the leader to allow enough autonomy for groups to innovate as well as encourage tight controls for implementation of ideas, thus practicing transformational leadership. The engineering participants from the MNC also expressed the significance of time it took to establish the trust with ODM designers. It was expressed that it took at least two design cycles, or three to five years, for the communication and risk taking to be established. Part of this experience led to the reduction of design cycle time once the trust had been established.

Another example is the influence of the degree of collectivism/individualism. The U.S. culture tends toward the highly individualistic and displays attributes of autonomy and independence (Triandis, 2001). However, in the findings the MNC engineering leaders expressed the need to relate significantly with the ODM engineers and develop guanxi to complete projects. The effort of the MNC leaders to become part of the collectivist group consisted of spending years building relationships of trust and empowerment. In the outsourcing of manufacturing, the leaders would be less relational and emphasize a transactional style of emphasizing the task without elucidating a vision. The participants expressed that since manufacturing consisted of codified knowledge, the task was easily communicated, whereas in design innovation, face-to-face meetings and communications were important.

\section{CONCLUSION}

The purpose of this paper was to contribute to the understanding of leadership of international R\&D outsourcing. Two research questions were formulated: what type of leadership approach is best for leading $\mathrm{R} \& \mathrm{D}$ outsourcing from the US to Asia in the PC industry? And, how is the leadership approach affected by cultural characteristics?

Based upon the literature review, it was concluded that the leadership style is related to two aspects: the type of activity and national cultural characteristics. R\&D activities in general require a transformational approach whereas manufacturing activities can be managed with a transactional approach. The U.S. culture fits with a transformational approach whereas in for example China, a transactional approach fits better with the culture. This leads to the question of trade-off; what leadership style is best when conducting $R \& D$ activities in for example China? The type of activity fits best with a transformational approach but the culture fits best with a transactional approach. The purpose of this paper is to examine both factors simultaneously and 
determine the trade-off issue instead of the previous studies which looked at one of the two factors.

The method followed in this study was the case study method. This method has certain limitations, in particular related to generalizability, some caution is therefore necessary and more studies may be needed to broadly test the developed model. The case studies focussed on two different projects in Asia, one in China and one in Taiwan.

In the first case (China) a transformational leadership approach was used by the US MNC. Thus, the approach used in the US was also applied in China despite the mismatch with the Chinese culture. In other words, it was possible for the MCN leadership to overcome the many cultural differences. In the second case (Taiwan) a transformational approach was also followed. However, several transactional elements were also implemented (for example bonuses for on-time design completion) but these had limited success. In other words, the approach that had a more natural fit with the Taiwanese culture had limited success. Based on these findings it can be concluded that the characteristics of R\&D work are 'more important' for determining leadership style than the culture to which the R\&D is being outsourced. However, in order to apply a transformational leadership style, many cultural differences had to be overcome and this required a significant amount of time. Thus, while a transformational approach seemed to be the best approach, it did require much more time to develop than initially envisioned.

In addition to these findings, it was also discovered that the MCN used a transactional approach within its own organization once outsourcing took place. This was contrary to what was expected based upon the literature review related to the cultural background (USA) as well as the type of activity (R\&D). The results indicated that this leadership style was not very effective thus confirming the literature on leadership of R\&D activities.

From a theoretical perspective this paper makes several contributions. This study showed that the leadership style used was primarily determined by the type of activity and that culture was less important and cultural differences could be overcome. Another contribution that this paper made is that a conceptual model was introduced that distinguishes leadership practices for outsourcing R\&D compared to manufacturing which has been the main focus of outsourcing studies. The important contribution in this regard is the notion that different types of activities call for different leadership approaches. This has important implications because for example a transformational leadership style requires more communication than a transactional leadership style. Based on this, it can be expected that outsourcing $\mathrm{R} \& \mathrm{D}$ to China is more difficult and more time-consuming than outsourcing manufacturing to China.

The model may be useful for MNC practitioners considering an ODM approach in reaching their strategic goals. In particular, the findings can be applied by PC industry managers in the future who are considering the ODM model or who are making allowance for the potential of outsourcing R\&D following already established outsourced manufacturing.

\section{REFERENCES}

Bader, M.A. (2008), Managing intellectual property in inter-firm R\&D collaborations in knowledge intensive industries, International Journal of Technology Management 41(3/4), pp. 311-335.

Bass, B. M., \& Riggio, R. E. (2006). Transformational leadership (2nd ed.). Mahwah, NJ: Lawrence Erlbaum.

Brown, D., \& Wilson, S. (2005). The black book of outsourcing: How to manage the changes, challenges, and opportunities. Hoboken, New Jersey: Wiley \& Sons.

Cheng, J.L.C. and Bolon, D.S. (1993), The management of multinational R\&D: a neglected topic in international business research, Journal of International Business Studies 24(1), pp. 1-18.

Dedrick, J., \& Kraemer, K. L. (2006). 'Is production pulling knowledge work to China? A study of the notebook industry'. Retrieved November 2, 2007, from: http://ieeexplore.ieee.org/search/wrapper.jsp?arnumber=1657 905

Dedrick, J., \& Kraemer, K. L. (2008).Globalization of innovation: The personal computing industry. Retrieved December 27, 2009 ,

from http://papers.ssrn.com/sol3/papers.cfm?abstract_id=1125025

Doyle, M.E. \& Smith, M.K. (1999). Born and bred'? Leadership, heart and informal education. London: YMCA George Williams College for the Rank Foundation.

Ernst, D. (2005), Pathways to innovation in Asia's leading electronics-exporting countries - a framework for exploring drivers and policy implications, International Journal of Technology Management 29(1/2), pp. 6-20.

Ernst, D., \& Kim, L. (2002). Global production networks, knowledge diffusion, and local capability formation. Research Policy 31(8/9), pp. 1417-1429.

Feller, J. Et al. (2009), Inter-partner relationship, knowledge transfer mechanisms, and improved capability to manage R\&D alliances: evidence from the telecommunications industry, International Journal of Technology Management 47(4), pp. 346-370.

Florida, R. (1997). The globalization of R\&D: Results of a survey of foreign-affiliated R\&D laboratories in the USA. Research Policy 26(1), pp. 85-103.

Furu, P. (2001), Drivers of competence development in different types of multinational R\&D subsidiaries, Scandinavian Journal of Management 17 pp. 133-149.

Grevesen, C.W. and Damanpour, F. (2007), Performance implications of organisational structure and knowledge sharing in multinational $\mathrm{R} \& \mathrm{D}$ networks, International Journal of Technology Management, 38(1/2), pp. 113-136.

Gupta, V., Carl, D., \& Javidan, M. (2004). 'Power distance'. In R. J. House, P. J. Hanges, M. Javidan, P. W. Dorfman, \& V. Gupta (Eds.), Culture, leadership, and organizations: The GLOBE study of 62 societies (pp. 513-563). Thousand Oaks, CA: Sage.

Hannah, S. T., \& Lester, P. B. (2008). A multilevel approach to building and leading learning organizations. The Leadership Quarterly 20(1), pp. 34-48.

Hartog, D. N. D. (2004). Assertiveness. In R. J. House, P. J. Hanges, M. Javidan, P. W. Dorfman, \& V. Gupta (Eds.), Culture, leadership, and organizations: The GLOBE study of 62 societies (pp. 395-436). Thousand Oaks, CA: Sage.

Hofstede, G. (1997). Cultures and organizations. New York: McGraw-Hill.

Hofstede, G. (2001). Culture's consequences: Comparing values, behaviors, institutions, and organizations across nations (2nd ed.). Thousand Oaks, CA: Sage.

Hofstede, G., \& Hofstede, G. J. (2005). Cultures and organizations: Software of the mind. Intercultural 
cooperation and its importance for survival (2nd ed.). New York: McGraw-Hill.

House, R. J. (2004). Introduction. In R. J. House, P. J. Hanges, M. Javidan, P. W. Dorfman, \& V. Gupta (Eds.), Culture, leadership, and organizations: The GLOBE study of 62 societies (pp. 1-7). Thousand Oaks, CA: Sage.

Jung, D., Chow, C. C., \& Wu, A. (2003). The role of transformational leadership in enhancing organizational innovation: Hypotheses and some preliminary findings. The Leadership Quarterly 14(4-5), pp. 525-544.

Jung, D., Wu, A., \& Chow, C. C. (2008). Towards understanding the direct and indirect effects of CEOs' transformational leadership on firm innovation. The Leadership Quarterly 19 (5), pp. 582-594.

Kahai, S. S., \& Avolio, B. J. (2008). Effects of leadership style and anonymity on the discussion of an ethical issue in an electronic meeting system context. In S. Weisband (Ed.), Leadership at a distance: Research in technologicallysupported work (pp. 97-125). New York: Lawrence Erlbaum Associates.

Kelley, C. (2004). High-technology manufacturing and U.S. competitiveness. Santa Monica: RAND Corporation.

Leifer, R., O'Connor, G. C., \& Rice, M. (2001). Implementing radical innovation in mature firms: The role of hubs. Academy of Management Executive 15(3), pp. 102-113.

Liu, M., \& Chen, S. (2003). International $R \& D$ deployment and locational advantage: A case study of Taiwan. Retrieved February 10, 2009, from http://www.nber.org/papers/w10169

Lynn, S., \& Salzman, H. (2007). "Innovation shift" to the emerging economies: Cases from IT and heavy industries. Retrieved November 18, 2008, from http://policy.rutgers.edu/faculty/salzman/1001109_innovation _shift.pdf

Makri, M., \& Scandura, T. A. (2010). Exploring the effects of creative CEO leadership on innovation in high-technology firms. The Leadership Quarterly 21 pp. 75-88.
Monczka, R., Trent, R. \& Handfield, R. (2002). Purchasing and supply chain management, second edition. Cincinnati: SouthWestern.

Seidman, I. (2006). Interviewing as qualitative research: A guide for researchers in education and the social sciences (3rd ed.). New York: Teachers College Press.

Shaw, J. B. (1990). A cognitive categorization model for the study of intercultural management. The Academy of Management Review 15(4), pp. 626-645.

Stake, R. E. (1995). The art of case study research. Thousand Oaks, CA: Sage.

Sully de Luque, M., \& Javidan, M. (2004). Uncertainty avoidance. In R. J. House, P. J. Hanges, M. Javidan, P. W. Dorfman, \& V. Gupta (Eds.), Culture, leadership, and organizations: The GLOBE study of 62 societies (pp. 602-644). Thousand Oaks, CA: Sage.

Thursby, J., \& Thursby, M. (2006). Here or there? A survey of factors in multinational $R \& D$ location. Retrieved November 10, 2008, from http://www.nap.edu/catalog/11675.html

Triandis, H. C. (2001). Individualism-collectivism and personality. Journal of Personality 69(6), pp. 907-924.

Van Maurik, J. (2001). Writers on leadership. London UK, Penguin.

Vonortas, N.S. and Okamura, K. (2009), Research partners, International Journal of Technology Management 46(3/4), pp. 280-306.

Wadhwa, V., Gereffi, G., Rissing, B., \& Ong, R. (2007). Where the engineers are. Issues in Science and Technology 23(3), pp. 73-84.

Wu, F-S (2007), Internationalisation of research and development: the case of Taiwanese firms, International Journal of Technology Management 39(3/4), pp. 297-310.

Zhao, W., \& Arvanitis, R. (2010). The innovation and learning capabilities of Chinese firms: Technological development in the automobile and electronics industries, Chinese Sociology and Anthropology 42(3), pp. 6-27

Dr. Cliff Allen is Academic Director of the Masters of International Management Graduate Program in the School of Business at Portland State University. He holds a BS and MA in Economics from San Jose State University and received his PhD in Leadership Studies from Gonzaga University. He has over 27 years of experience in the technology industry, including executive positions at Solectron, 3Com, Palm Computing, and General Dynamics.

Dr. Harm-Jan Steenhuis is a Professor of Management at Eastern Washington University. He received his MSc in Industrial Engineering and Management and his PhD in International Technology Transfer from the University of Twente, the Netherlands. He is currently primarily involved in research on international technology management. 